\title{
Immune Reconstitution Inflammatory Syndrome during the First Six Months of Receiving Antiretroviral in HIV-Infected Individuals: A Retrospective Study
} Faustine Tungaraza ${ }^{1 *}$, Augustino S. Kahere ${ }^{1}$, George M. Bwire ${ }^{1 *}$, Doreen Mloka ${ }^{1}$, Fatuma F. Felician ${ }^{1}$, Liberata Mwita ${ }^{1}$, Raphael Z. Sangeda ${ }^{1}$, Esther J. Ndegeulaya ${ }^{1}$, Fidelis F. Manyaki ${ }^{1}$, Manase Kilonzi ${ }^{2}$, Wigilya P. Mikomangwa ${ }^{2}$, Hamu J. Mlyuka ${ }^{2}$, Alphonce I. Marealle ${ }^{2}$, Ritah Mutagonda ${ }^{2}$, Anna Sanga ${ }^{3}$, Kennedy D. Mwambete ${ }^{1}$

${ }^{1}$ Department of Pharmaceutical Microbiology, School of Pharmacy, Muhimbili University of Health and Allied Sciences, P.O. Box 65013, Dar es Salaam, Tanzania

${ }^{2}$ Department of Clinical Pharmacy and Pharmacology, School of Pharmacy, Muhimbili University of Health and Allied Sciences, P.O. Box 65013, Dar es Salaam, Tanzania.

${ }^{3}$ Department of Internal Medicine, Mloganzila, Muhimbili National Hospital, P.O. Box 65000, Dar es Salaam, Tanzania.

* Corresponding Author: George M. Bwire, Department of Pharmaceutical Microbiology, Muhimbili University of Health and Allied Sciences, Tanzania. E-mail: gbwire@muhas.ac.tz

Received date: July 24, 2019; Accepted date: August 02, 2019; Published date: August 14, 2019

Citation: Faustine Tungaraza, Augustino S. Kahere, George M. Bwire, Doreen Mloka, Fatuma F. Felician, Liberata Mwita et al.(2019) Immune reconstitution inflammatory syndrome during the first six months of receiving antiretroviral in HIV-infected individuals: a retrospective study. J. Immunology and Inflammation Diseases Therapy, 2(3): Doi: 10.31579/2637-8876/014.

Copyright:@2019 Faustine Tungaraza et al . This is an open-access article distributed under the terms of The Creative Commons Attribution License, which permits unrestricted use, distribution, and reproduction in any medium, provided the original author and source are credited.

\section{Abstract}

Introduction: Immune reconstitution inflammatory syndrome (IRIS) is referred to as the flare up of an underlying, previously undiagnosed infection or the worsening of a previously treated infection soon after antiretroviral therapy (ART) is started. Information about the prevalence and associated risk factors for IRIS in resource-constrained countries like Tanzania where access to ART is increasing is scarce. Therefore, this study was conducted to determine the prevalence and risk factors associated with IRIS among patients attending care and treatment clinic at Muhimbili National Hospital (CTC-MNH).

Methods: A retrospective cohort study was conducted in patients receiving highly active antiretroviral therapy (HAART) who attended CTCMNH between July 2016 and June 2018. Mann Whitney test was used to compare median CD4+ cells count and viral load at baseline and after 6 months of treatment. Associated factors were analysed using multi-logistic regression. Statistics were done using GraphPad Prism 7 software and a p-value $<0.05$ was considered statistically significant.

Results: Of 318 patients, $8.5 \%$ encountered IRIS. Compared to baseline readings, there were significant increases in CD4+ cells (P < 0.0001) and decrease in viral load count $(\mathrm{P}<0.0001)$. Patients who did not adhere to HAART were more likely to develop IRIS [Adjusted Odds Ratio (AOR) $=$ $4.2,95 \% \mathrm{CI} ; 1.14-15.60, \mathrm{P}=0.03]$.

Conclusion: This study found relatively low prevalence of IRIS as compared to those reported elsewhere. Moreover, poor adherence to HAART was found to be a risk factor for IRIS.

Key words: IRIS; muhimbili national hospital; HAART; prevalence; risk factors

\section{Introduction}

The introduction of highly active antiretroviral therapy (HAART) in human immunodeficiency virus/acquired immunodeficiency syndrome (HIV/AIDS) patients leads to dramatic reduction in plasma viral load, progression to AIDS, overall mortality [1] and provide partial restoration of overall immune function [2] . Furthermore, these immunological changes correlate with reduction in the frequency of opportunistic infections and prolong survival [3].

In the mid-1990s, clinicians noticed that certain patients deteriorated after starting HAART despite having decreasing HIV-1 RNA levels and raising CD4 cell counts [4]. In these patients, use of HAART resulted to a pathological inflammatory response to either previously treated infections or subclinical -opportunistic infections [5]. This inflammation could result in deleterious clinical outcomes known as immune reconstitution diseases (IRD) or immune reconstitution inflammatory syndrome (IRIS) [6]. Several infectious agents such as cytomegalovirus virus, Mycobacterium tuberculosis or Mycobacterium avium complex, and Cryptococcus neoformans have been associated with IRIS in HIV/AIDS patients starting HAART $[4,7,8]$.
Although, information regarding IRIS prevalence and risk factors for developing IRIS and long term clinical outcomes is scarce, it is estimated that people living with HIV (PLHIV) and initiated with HAART have an IRIS prevalence ranging between $10-30 \%$ [5]. The variations in reported frequency are due to differences in case definitions, and more importantly differences in study populations with different risk profile and underlying burden of opportunistic infections [8]. It is expected that IRIS will be more common in low and middle-income countries, Tanzania in particular where access to antiretroviral therapy (ART) is increasing $[9,10]$.

Therefore, the current study was conducted to determine the prevalence and risk factors associated with IRIS at Muhimbili National Hospital, care and treatment clinic.

\section{Methods}

\section{Study design, area and subjects}

A retrospective study was conducted in patients on HAART attending care and treatment clinic (CTC) at Muhimbili National Hospital (MNH) between July 2016 and June 2018. Since 2016 MNH-CTC adopted the use of both CD4+ cells counts and viral load as HIV/AIDS prognostic tests. Moreover, the implementations of diagnose and treat was still at infancy stage. 
MNH has a separate CTC with more than 18000 PLHIV on follow-up where about 500 PLHIV visit clinic per week. All patients received HAART for at least six months were eligible to participate in this study.

\section{Sample size and sampling technique}

The sample size was calculated using the prevalence of $31.7 \%$ [5], where the marginal of error was set to be 5. Patients ${ }^{\text {ee }}$ records at MNH records department were retrieved from the Jeeva HIV-care database $(\mathrm{MNH}$, Tanzania). Information of patients enrolled between July 2016 and June 2018 were downloaded from the database then sampled randomly to attain the required sample size. The patient number was recorded then the respective file was reviewed so as to obtain the required information such as social demographics, lab investigations and treatment history. Information, which was not found in the patient's file, was obtained from searching the specific information in the Jeeva HIV-care database.

\section{Data collection}

\section{Development of case report forms/ checklist}

Case report forms (CRFs) were developed to collect information including demographic, clinical, laboratory, drug administered and comorbidities. The CRFs were developed after comprehensive literature review of the studies, which described the association between IRIS and treatment outcomes $[5,7,8]$. Additionally, the CRFs were first validated and tested for answering the objectives of the study by selecting 10 patients" files randomly from 318 - sampled files.

\section{Determination of IRIS}

IRIS was determined after reviewing the patientse files using criteria described elsewhere [6]. Briefly, new onset or worsening symptoms of an infection or inflammatory condition after start of HAART, progression of organ dysfunction or enlargement of pre- existing lesions after definite clinical improvement with pathogen-specific therapy prior to HAART and exclusion of treatment toxicity and new diagnoses and exaggerated inflammatory reaction i.e. severe fever or painful lesions were documented as IRIS. Two independent researchers reviewed the files, when the differences on documenting IRIS cases occurred, consensus were reached after consulting an experienced Clinician.

\section{Documentation of adherence}

Adherence was recorded as found in patientse files. At MNH care and treatment clinic, adherence is commonly determined by patient"s selfreporting method. Based on that method more than 95\% HAART take, coupled with clinical assessments. A Clinician assigned the status of "good adherence" (more than 95\% HAART use in past seven and/or thirty days)" or "not good/ non-adherence" (less than 95\% HAART use in the past seven and thirty days)" to the attended patient[9].

\section{Definition of operational terms}

Body mass-index (BMI): Calculated as the ratio of baseline weight $(\mathrm{kg})$ and height $\left(\mathrm{m}^{2}\right)$ of the patient obtained as documented in the file.

Immunological failure: This was the CD4+cells count of less than 350 cells $/ \mathrm{mm}^{3}$ for two consecutive measurements 6 months after initiation of antiretroviral [9].

Virological failure: This was the failure to suppress viral load to less than $1000 \mathrm{HIV}-\mathrm{RNA}$ copies/ml for two consecutive measurements within 6 months after initiation of antiretroviral [9].

Treatment failure: referred to either clinical failure occurrence/ persistence of HIV related opportunistic infections or immunological and/or virological failures [9].

\section{Data management and analysis}

Data collected on CRFs were crosschecked for the completeness then entered manually in Microsoft excels spreadsheet followed by exporting them to GraphPad (Prism 7 software, USA) for analyzing social demographics and laboratory findings. Undocumented data were coded as missing information. Mean and percentage were used to summarize social demographic characteristics whereas Mann Whitney test was used to compare median CD4+ cells counts and viral load at baseline and six months after of receiving HAART.
Associations between various factors with IRIS were analyzed using multi-logistic regression. Variables with $p$ value less than 0.25 on univariate analysis were entered to multivariate analysis. Type 1 error for significance was 0.05 .

\section{Ethical consideration}

Muhimbili University of Health and Allied Sciences (MUHAS) Research and Publication committee approved this study. (Ref. No. DA.282/298/01.C/). Permission to access patients ${ }^{\text {ee }}$ files was requested from MNH Research and Publications Committee. Names and other personal details including patients ${ }^{\text {ec }}$ hospital number were not disclosed for confidentiality purpose; thus, most information was coded and entered into the computer for statistical analysis.

\section{Results}

\section{Subjects recruitment flow chart}

As of June 2018, a total of 18813 PLHIV were attending care and treatment clinic at $\mathrm{MNH}$. Of $18813,2.4 \%$ [number $(\mathrm{n})=457$ ] were enrolled between July 2016 and June 2018 and 93\% $(n=425)$ of the enrolled patients were initiated HAART, then 318 patientse files of those receiving HAART were reviewed to determine the prevalence and risk factors for IRIS (Figure 1).

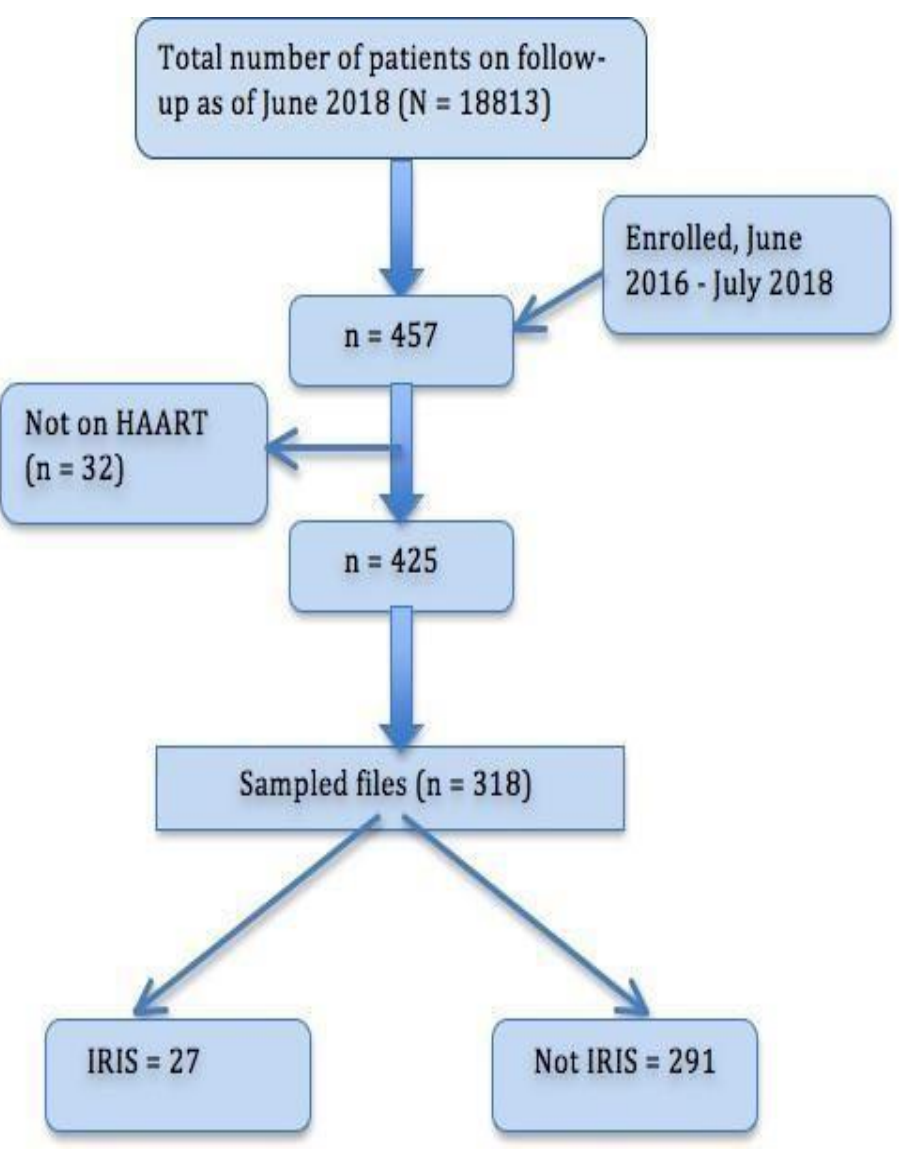

Figure 1: Subjects recruitment flow chart. A total of 318 files of patients attended clinic between July 2016 and June 2018 were sampled and reviewed.

\section{Patients' social demographic information}

Overall 318 files of PLHIV attended CTC at MNH between July 2016 and June 2018 were reviewed. The patients ${ }^{e e}$ age [ \pm standard deviation $( \pm$ SD $\left.)\right]$ was 38.3 years (15.7) with the mean BMI $( \pm \mathrm{SD})$ of $24.5 \mathrm{~kg} / \mathrm{m}^{2}(6.6)$. Majority of the participants $(42.1 \%, \mathrm{n}=102)$ were married while the number of females $(55.7 \%, \mathrm{n}=177)$ was higher. Most of the participants $(35.7 \%, \mathrm{n}=104)$ were at WHO AIDS first stage and $77.7 \%(\mathrm{n}=247)$ were using Tenofovir based regimen (TDF). Fewer cases of co-infection (7.9\%, $\mathrm{n}=25)$ were documented at the baseline where most $(27.3 \%, \mathrm{n}=6)$ of the participants were co-infected with pneumonia (Table 1). 
JImmunology and Inflammation Diseases Therapy

\begin{tabular}{|c|c|c|c|}
\hline Variable & \multicolumn{2}{|c|}{ Measurement } & Value \\
\hline Age (year) & \multicolumn{2}{|c|}{ Mean $( \pm$ SD) } & $38.3(15.7)$ \\
\hline \multirow[t]{2}{*}{ Sex } & \multicolumn{2}{|l|}{ Male, n (\%) } & $141(44.3)$ \\
\hline & \multicolumn{2}{|c|}{ Female, n (\%) } & $177(55.7)$ \\
\hline BMI $\left(\mathrm{kg} / \mathrm{m}^{2}\right)$ & \multicolumn{2}{|c|}{ Mean $( \pm$ SD $)$} & $24.5(6.6)$ \\
\hline \multirow[t]{4}{*}{ Marital status } & \multicolumn{2}{|c|}{ Single, n (\%) } & $99(40.9)$ \\
\hline & \multicolumn{2}{|c|}{ Married, n (\%) } & $102(42.1)$ \\
\hline & \multicolumn{2}{|c|}{ Widow, n (\%) } & $26(10.7)$ \\
\hline & \multicolumn{2}{|c|}{ Divorced, n (\%) } & $15(6.2)$ \\
\hline \multirow{3}{*}{$\begin{array}{l}\text { HAART } \\
\text { regimen }\end{array}$} & \multicolumn{2}{|c|}{ Tenofovir regimen, $\mathrm{n}(\%)$} & $247(77.7)$ \\
\hline & \multicolumn{2}{|c|}{ Zidovudine regimen, $\mathrm{n}(\%)$} & $19(6.0)$ \\
\hline & \multicolumn{2}{|c|}{ Abacavir regimen, $\mathrm{n}(\%)$} & $52(16.4)$ \\
\hline \multirow[t]{4}{*}{ WHO stage } & \multicolumn{2}{|l|}{$\mathrm{I}, \mathrm{n}(\%)$} & $104(35.7)$ \\
\hline & \multicolumn{2}{|l|}{ II, n (\%) } & $66(22.7)$ \\
\hline & \multicolumn{2}{|l|}{ III, n (\%) } & $61(21.0)$ \\
\hline & \multicolumn{2}{|l|}{ IV, n (\%) } & $60(20.6)$ \\
\hline \multirow[t]{9}{*}{ Co-infection } & \multirow[t]{8}{*}{ Yes, n (\%) } & Type of infection & \\
\hline & & Herpes & $3(13.6)$ \\
\hline & & TB & $4(18.2)$ \\
\hline & & Pneumonia & $6(27.3)$ \\
\hline & & Oral fungal infection & $4(18.2)$ \\
\hline & & Skin fungal infection & $4(18.2)$ \\
\hline & & Others & $1(4.5)$ \\
\hline & & Total Yes & $25(7.9)$ \\
\hline & \multicolumn{2}{|l|}{ No, n (\%) } & $293(92.1)$ \\
\hline
\end{tabular}

Table 1: Participants"e social demographic information

\section{Clinical characteristics for cohort of patients on HAART}

The median CD4+ cell count [interquartile range (IQR)] at baseline and after six months were 237 cells $/ \mathrm{mm}^{3}(126-438)$ and $391 \mathrm{cells} / \mathrm{mm}^{3}(224$ $647)$ respectively, $\mathrm{P}<0.0001$. The viral load count $\left(\log _{10}\right.$ copies $\left./ \mathrm{ml}\right)$ at the baseline and after six months were 3.4 (2.5-4.7) and 2.4 (1.3-3.6) respectively, $\mathrm{P}<0.0001$. Among 318 studied patients the prevalence of IRIS was found to be $8.5 \%$. The highest numbers of patients were reported to have good adherence to HAART use by $48.8 \%(n=120)$ (Table 2).

\begin{tabular}{|c|c|c|c|c|}
\hline \multicolumn{3}{|l|}{ Variable } & Value & P value \\
\hline \multirow{6}{*}{\begin{tabular}{|l|} 
Laboratory \\
measurem \\
ents
\end{tabular}} & \multirow{3}{*}{$\begin{array}{l}\text { CD4+ cell } \\
(\text { cells/mm³) } \\
\text { Median (IQR) }\end{array}$} & At baseline & $237(126-438)$ & \multirow{3}{*}{$P<0.0001$} \\
\hline & & & & \\
\hline & & After 6 months & $391(224-647)$ & \\
\hline & \multirow{3}{*}{\begin{tabular}{|lr} 
Viral & load \\
$\left(\log _{10}\right.$ copies/ml) & \\
Median & (IQR)
\end{tabular}} & At baseline & $3.4(2.5-4.7)$ & \multirow{3}{*}{$\mathrm{P}<0.0001$} \\
\hline & & & & \\
\hline & & After 6 months & $2.4(1.3-3.6)$ & \\
\hline IRIS & \multicolumn{2}{|l|}{$\mathrm{n}(\%)$} & $27(8.5)$ & \\
\hline \multirow[t]{3}{*}{ Adherence } & \multicolumn{2}{|l|}{ Good, n (\%) } & $120(48.8)$ & \\
\hline & \multicolumn{2}{|l|}{ Not good, n (\%) } & $20(6.3)$ & \\
\hline & \multicolumn{2}{|l|}{ Undocumented } & $143(45)$ & \\
\hline
\end{tabular}

Table 2: Clinical characteristics for cohort of patients on HAART for at least 6 months.

\section{Factors associated with IRIS}

The study found no association between age, BMI, CD4+ cells count, viral load at baseline and WHO AIDS stage and IRIS ( $>0.05)$. With regards to adherence, patients who did not adhere to HAART had four times chances to get IRIS [Adjusted Odds Ratio $(\mathrm{OR})=4.2,95 \% \mathrm{CI}$; 1.14 $15.60, \mathrm{P}=0.03$ ] (Table 3).

\begin{tabular}{|c|c|c|c|}
\hline \multicolumn{2}{|l|}{ Factor } & $\begin{array}{l}\text { Adjusted Odds Ratio } \\
\text { (AOR) 95\% CI }\end{array}$ & $P$ value \\
\hline \multicolumn{2}{|l|}{ Age (years) } & $0.9(0.9,1.1)$ & $\mathrm{P}=0.827$ \\
\hline \multicolumn{2}{|c|}{ BMI $\left(\mathrm{kg} / \mathrm{mm}^{2}\right)$} & $0.9(0.77,1.2)$ & $\mathrm{P}=0.808$ \\
\hline \multicolumn{2}{|c|}{$\begin{array}{l}\text { CD4+ cells count at baseline } \\
\left(\text { cells } / \mathrm{mm}^{3}\right)\end{array}$} & $1(0.99,1.0)$ & $\mathrm{P}=0.736$ \\
\hline \multicolumn{2}{|c|}{$\begin{array}{l}\text { Viral load at baseline } \\
\text { (copies } / \mathrm{ml})\end{array}$} & $1(1,1)$ & $\mathrm{P}=0.921$ \\
\hline \multirow{2}{*}{$\begin{array}{l}\text { Adherenc } \\
\mathrm{e}\end{array}$} & Yes & $1.8(0.74,4.4)$ & $\mathrm{P}=0.192$ \\
\hline & No & $4.2(1.14,15.60)$ & $\mathrm{P}=0.031 *$ \\
\hline \multirow{3}{*}{$\begin{array}{l}\text { WHO } \\
\text { AIDS } \\
\text { stage }\end{array}$} & First & $0.45(0.12,1.77)$ & $\mathrm{P}=0.254$ \\
\hline & Second & $0.42(0.1,1.78)$ & $\mathrm{P}=0.240$ \\
\hline & Third & $0.5(0.11,2.3)$ & $\mathrm{P}=0.376$ \\
\hline
\end{tabular}

Table 3: Multi-logistic regression analysis of IRIS associated factors

\section{Discussion}

Hence, an increased risk of HIV/AIDS and IRIS [8]. Moreover, increased use of HAART in LMICs, estimated to increase the incidences of IRIS [9]. Tanzania is among the countries where the use of ARV is increasing [9]. Therefore, a two years retrospective study (2016-2018) was conducted to determine the prevalence and factors associated with IRIS in patients attending care and treatment clinic at MNH. To the best of our knowledge this is the first study to report the prevalence and risk factors for IRIS at MNH.

The current study found a prevalence of IRIS to be $8.5 \%$. This is a small percent when compared to the finding by Shelburne et al. 2005 [5] which reported the the prevalance of about $30 \%$. Another study which was conducted in Perunian children documented a prevalance of $20 \%$ [12]. The differences between the studies may have been contributed by the different in study design [5] and difference in the study population [12]. Additionally the study participants in this study majority $(35.7 \%)$ were at the first WHO AIDS stage and the mean age of participants in the current retrospective study was 38.3 years.

This study found a significant increase in CD4+ cells count and decrease in viral load six months after initiations of HAART. This concured to the study conducted in Rwanda which, reported similar clinical outcomes [13]. Findings from the current study may have been contributed by good adhrence reported to most of the patients $(48.8 \%)$ and most of them being enrolled at WHO AIDS first stage (35.7\%)

In determining the risks factors associated with IRIS, only non-adherence to HAART was associated with the risk of getting IRIS. Although the risks factors for getting IRIS are still unclear [5], but different factors such as low CD4+ counts, high viral load and presence of subclinical infections have been hypothesized to be responsible $[6,8]$. However the current study found no association between IRIS and these factors.

This study was limited by lack of standard definition of IRIS with objective biomarkers for diagnosis. Conforming to the national guidelines, publisher articles and having multiple reviewers to agree on suspected IRIS cases minimized the limitation. In addition, adherence was limited to patient"s memory but other parameters such as clinical assessment and laboratory investigations were included in assigning good or non- adherence. Moreover, because the design of the study was retrospective, some of the CD4 lymphocyte counts and HIV viral loads were not available at baseline, after HAART initiation and at the time of the IRIS event. Also, the number of eligible participants in the cohort was small to make firm conclusions about specific risk factors.

\section{Conclusion}

This study found relatively low prevalence of IRIS as compared to those reported elsewhere. Moreover, non-adherence to HAART was found to be a risk factor for IRIS. Recommendation, Clinicians should be aware of both the unmasked subclinical infections as well as the paradoxical 
J Immunology and Inflammation Diseases Therapy

Recrudescence of successfully treated infections in HIV-infected patients shortly after initiating HAART. Future study on specific risk factors is recommended so that patients who are at highest risk of IRIS can be identified and treated promptly.

\section{Abbreviations}

AIDS: Acquired Immune Deficiency Syndrome; CD4: Cluster of Differentiation; CTC: Care and Treatment Clinic; HAART: Highly Active Antiretroviral Therapy; HIV: Human Immunodeficiency Virus; IRIS: Immune Reconstitution Inflammatory Syndrome; MNH: Muhimbili National hospital; PLHIV: People Living with HIV; RNA:

\section{References}

1. Hogg, R. S. et al. (2001). 'Rates of disease progression by baseline CD 4 cell count and viral load after initiating triple-drug therapy', Journal of the American Medical Association. 286(20): 2568-2577.

2. Asfaw, A. et al. (2015). CD4 cell count trends after commencement of antiretroviral therapy among HIV-infected patients in Tigray, Northern Ethiopia: A retrospective cross-sectional study', PLoS ONE.

3. Khienprasit, N. et al. (2011). 'Incidence and risk factors of antiretroviral treatment failure in treatment-naïve HIV-infected patients at Chiang Mai University Hospital, Thailand', AIDS Research and Therapy. 8: 1-7.

4. Sharma, S. and Soneja, (2011). M. HIV \&amp; immune reconstitution inflammatory syndrome (IRIS)', The Indian Journal of Medical Research. 866.

5. Shelburne, S. A. et al. (2005). Incidence and risk factors for immune reconstitution inflammatory syndrome during highly active antiretroviral therapy.399-406.

6. Lewis J. Haddow, Philippa J. Easterbrook, Anisa Mosam, Nonhlanhla G. Khanyile, Raveen Parboosing, Pravikrishnen Moodley, Mahomed-Yunus S. Moosa,( 2009). Defining Immune Reconstitution Inflammatory Syndrome: Evaluation of Expert Opinion versus 2 Case Definitions in a South African Cohort, Clinical Infectious Diseases, Volume 49, Issue 9, 15 November, Pages 1424-1432,
Ribonucleic Acid; TB: Mycobacterium tuberculosis; WHO: World Health Organization.

\section{Conflict of Interest}

Authors declare that there is no competing interest

\section{Acknowledgements}

We thank the MNH management for granting permission to access patients' files on care and treatment clinic and collect their information. More importantly, we acknowledge the cooperation received from Clinicians, Nurses and Health Records Department particularly $\mathrm{Mr}$ Geofrey Semu.

7. Laureillard, D. et al.(2013).Paradoxical tuberculosis-associated immune reconstitution inflammatory syndrome after early initiation of antiretroviral therapy in a randomized clinical trial, Aids, 27(16): $2577-2586$.

8. Valin, N. et al. (2010) 'Risk factors for "unmasking immune reconstitution inflammatory syndrome" presentation of tuberculosis following combination antiretroviral therapy initiation in HIVinfected patients,p.1519-1525.

9. United Republic of Tanzania. National Guidelines for Management of HIV/AIDS. 2017.

10. Marais, S. and Meintjes, G. (2015).'Immune reconstitution inflammatory syndrome (IRIS)', Clinical Infectious Disease, Second Editio. (12): 669-675.

11. Pelto, P. J., \& Pelto, G. H. (1997). Studying Knowledge, Culture, and Behavior in Applied Medical Anthropology. Medical Anthropology Quarterly, 11(2), 147-163.

12. Wang ME, Castillo ME, Montano SM, Zunt JR. (2009 Oct) Immune reconstitution inflammatory syndrome in human immunodeficiency virus-infected children in Peru. Pediatr Infect Dis J. 28(10): 900-3.

13. Rich, Michael L, Miller, Ann C, Niyigena, Peter, RN, Franke, Molly F, Niyonzima, Jean Bosco, Socci, Binagwaho, Agnes et al.( 2012) Excellent Clinical Outcomes and High Retention in Care Among Adults in a Community-Based HIV Treatment Program in Rural Rwanda. JAIDS Journal of Acquired Immune Deficiency Syndromes (3); 59(3): 35-42. 